\title{
Efeito de um programa de educação ambiental: o caso da bituca de cigarro*
}

\section{Alexandre Nascimento de Almeida ${ }^{1}$, Loyane Soares Neves ${ }^{2}$}

${ }^{1}$ Engenheiro Florestal. Professor Dr. Faculdade UnB de Planaltina. Universidade de Brasília (FUP/UnB). Área Universitária 1. Vila Nossa Senhora de Fátima. PlanaltinaDF (CEP 73300-000). E-mail: alexalmeida@unb.br.

${ }^{2}$ Gestora Ambiental. Graduada na Faculdade UnB de Planaltina. Universidade de Brasília (FUP/UnB). Área Universitária 1. Vila Nossa Senhora de Fátima. PlanaltinaDF (CEP 73300-000). E-mail: loyanesoares@gmail.com.

Resumo. O objetivo do trabalho é relatar o processo de implementação de um programa de educação ambiental na Universidade de Brasília - UnB relacionado aos males do cigarro realizado durante o mês de abril de 2013. A estrutura do programa abordou duas estratégias: (1) Prover condições para que os fumantes descartem as bitucas corretamente; (2) Conscientizar o público alvo dos malefícios do cigarro para o meio ambiente e para saúde. O indicador de controle da efetividade do programa foi a partir de respostas do público-alvo em questionários com perguntas fechadas em Escala de Likert, sendo comparadas as respostas antes e depois da implementação do programa por meio do teste não paramétrico de Mann-Whitney, bem como foi analisado a efetividade do programa em diferentes públicos, segmentados por gênero, idade e hábito de fumar. Exceto para os não fumantes, os resultados indicaram que o programa de educação ambiental modificou positivamente o conhecimento dos envolvidos em todos os outros segmentos analisados, conscientizando-os sobre os danos das bitucas de cigarro para o meio ambiente e dos males para a saúde do hábito de fumar.

Palavras-chaves: Educação Ambiental; Gestão Ambiental; Bitucas de cigarro.

Abstract. Effect of an environmental education program: the case of cigarette butt. The purpose of this paper is to report the implementation of an environmental education program at Brasilia University related to cigarette evils done during the month of April 2013. The structure of the program addressed two strategies: (1) Providing conditions or smokers discard the butts properly; (2) Educate the target community of the dangers of smoking to the environment and to health. Obtained control indicators from the questionnaires, comparing the responses before and after the environmental education program through the Mann-Whitney nonparametric test, as well as, was analyzed the effectiveness of the program in different audiences, segmented by gender, age and smoking habits. Except for public non-smoking, the results indicated that the environmental education program positively changed the

Recebido: 20/04/2015

Aceito:

$27 / 05 / 2016$

Publicado:

$30 / 06 / 2016$

Acesso Aberto Artigo completo

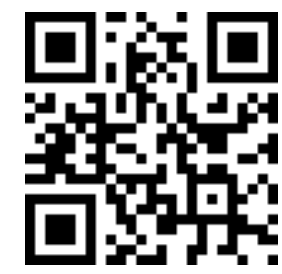

ORCID

(ㄷ) 0000-0002-9113-0729

Alexandre Nascimento de Almeida

(c) 0000-0002-1281-295X

Loyane Soares Neves

*Apresentado no V Congresso Brasileiro de Gestão Ambiental, Belo Horizonte/MG, 24 a 27/11/2014. 
knowledge of those involved in the different segments analyzed, making them aware about the harm of cigarette butts to the environment and cigarette harm to health.

Keywords: Environmental education; Environmental management; Cigarette butts.

\section{Introdução}

O termo "Educação Ambiental" foi registrado pela primeira vez há pouco mais de 50 anos na Grã-Bretanha, durante a Conferência de Educação realizada na Universidade de Keele, em 1965 (Czapski, 1998). Nesse período, a crise ambiental tornava-se cada vez mais evidente, principalmente em função da intensificação dos impactos ambientais das atividades humanas. Nesse contexto, a necessidade de introduzir na educação dos cidadãos os princípios básicos de ecologia e de conservação dos recursos naturais levou ao surgimento da educação ambiental (Layrargues, 2003). De lá pra cá, esse campo cresceu e diversificou-se, consolidando-se como um espaço de atividade e de saber, bastante conhecido tanto internacionalmente como nacionalmente.

Inexiste ainda uma conceituação perfeitamente delimitada e consensual do que seja educação ambiental. $O$ seu conceito ainda se encontra em fase de construção e, por essa razão, que existe uma pluralidade de definições para o termo educação ambiental, referindo a uma gama multifacetária de práticas educacionais relacionadas ao tema (Silva, 2008).

O sucesso de um programa de educação ambiental depende, além da capacidade pedagógica e do conhecimento sobre meio ambiente dos executores, do conhecimento das características do público-alvo; informações essas fundamentais para a gestão e delineamento de estratégias eficientes para qualquer programa dessa natureza. Esse pensamento é compartilhado por Silva e Leite (2008), que, segundo eles, para a realização de educação ambiental é necessário que o educador verifique a percepção ambiental dos atores sociais, promova um diagnóstico do meio em estudo e trace estratégias que abranjam toda a comunidade participante na busca de soluções para os problemas.

Na mesma linha, os resultados da pesquisa de Santos e Silva (2011) apresentaram a importância do conhecimento do público-alvo nas pesquisas de educação ambiental. De acordo com esses autores, mais da metade das pesquisas em educação ambiental entre 2005 e 2010 tiveram como objetivo fazer um diagnóstico do público-alvo ou avaliar a sua percepção ambiental. Um exemplo é o trabalho de Lopes et al. (2011), com base em um diagnóstico socioambiental em uma escola rural, explicaram os motivos do fracasso de ações prévias de cunho ambiental na escola, bem como, contribuíram para a construção de projetos pedagógicos que incluam a educação ambiental em escolas rurais.

Nesse sentido, o objetivo do trabalho é apresentar os resultados da implementação de um programa de educação ambiental na Faculdade UnB de Planaltina (FUP) relacionado aos males das bitucas de cigarro no meio ambiente, bem como, os males do fumo para a saúde, analisando os efeitos do programa em diferentes públicos, segmentados por gênero, idade e hábito de fumar, contribuindo assim para ampliação do conhecimento no campo da educação e socializando práticas que possam ser replicadas em outros contextos educacionais.

\section{Material e métodos}

\section{Estrutura do programa de educação ambiental}

O programa foi focado principalmente na redução do volume de bitucas (resíduo de cigarro consumido) que são descartadas incorretamente na Faculdade UnB de Planaltina e ocorreu durante todo o mês de abril de 2013. Para tanto, atuou-se na educação de toda 
comunidade acadêmica da FUP (professores, alunos e servidores) para $\mathrm{O}$ descarte correto das bitucas e na conscientização voltada para a redução do habito de fumar. O programa contou com duas estratégias:

\section{Prover as condições para que o público-alvo descarte as bitucas corretamente, cujas ações foram:}

- Depois de mapeado os locais com maior concentração de bitucas jogadas no chão, instalaram-se quatro caixas coletoras de bitucas de modo a facilitar a ação do fumante na sua utilização (Figura 1).

- Foram distribuídos, aleatoriamente entre homens e mulheres, 200 portabitucas portáteis para os fumantes durante intervalo das aulas e por meio de abordagens com professores e servidores, instruindo que, uma vez que o porta bituca estivesse cheio (capacidade de 30 bitucas), as bitucas deveriam ser dispensadas nas caixas coletoras (Figura 2).

2. Conscientizar o público-alvo dos malefícios da bituca de cigarro para o meio ambiente e do hábito de fumar para a saúde, por meio das seguintes atividades:

- Criação de uma fanpage na rede social Facebook intitulado "Projeto Rebituque-se". Nesse veículo de informação foram organizadas notícias pertinentes ao tema das bitucas de cigarro e seus impactos, o cronograma de atividades e os resultados alcançados do projeto. Também possibilitou um feedback rápido com o público alvo (Figura 3).

- Elaboração de 17 cartazes educativos com informações sobre os males das bituca de cigarro para o meio ambiente, afixados nos murais do campus (Figura 4).

- Exposição de 50 cartazes fornecidos pelo Ministério da Saúde nos locais de maior movimentação de pessoas com informações dos males do cigarro para a saúde (Figura 5).
- Exposição do assunto pessoalmente em sala de aula para grupos de alunos e individualmente para os professores e servidores, aproveitando o contato para distribuir os porta-bitucas e panfletos educativos sobre o tema (Figura 6).

\section{ambiental}

Custo do programa de educação

Devido à dificuldade de conseguir recursos externos, o programa de educação ambiental implantado foi relativamente modesto, sendo gasto a quantia de $\mathrm{R} \$ 26,00$ (vinte e seis reais), utilizados para impressão dos cartazes e folhetos educativos com conteúdo específico sobre os malefícios do descarte inadequado das bitucas de cigarro.

$\mathrm{O}$ custo não considerou os gastos com a mão-de-obra por tratar-se de um trabalho estudantil voluntário, bem como, não considerou $o$ material fornecido gratuitamente pelas parcerias conseguidas, destacando:

- Empresa Poiato Recicla, no fornecimento de quatro caixas coletoras específicas para as bitucas.

- Os Reciclerios, que forneceram os porta-bitucas portáteis.

- Ministério da Saúde, que forneceu os cartazes sobre os males do hábito de fumar para saúde.

Caso não houvesse as parceiras e contabilizando-se os gastos com a mão-deobra, o custo dos materiais utilizados no programa, em abril de 2013, seria de $\mathrm{R} \$$ $1.146,00$ (hum mil cento e quarenta e seis reais) (Tabela 1$)$.

\section{Avaliação do programa de educação ambiental}

Similar a Trajber e Costa (2001) e a Pedrini (2012) a avaliação da eficiência do programa ocorreu por meio da comparação de informações obtidas via questionário aplicado aleatoriamente antes e depois do programa de educação ambiental. A amostragem alcançada foi de 85 questionários respondidos antes do programa de educação ambiental e, mesmo número, após o programa. $\mathrm{O}$ questionário 


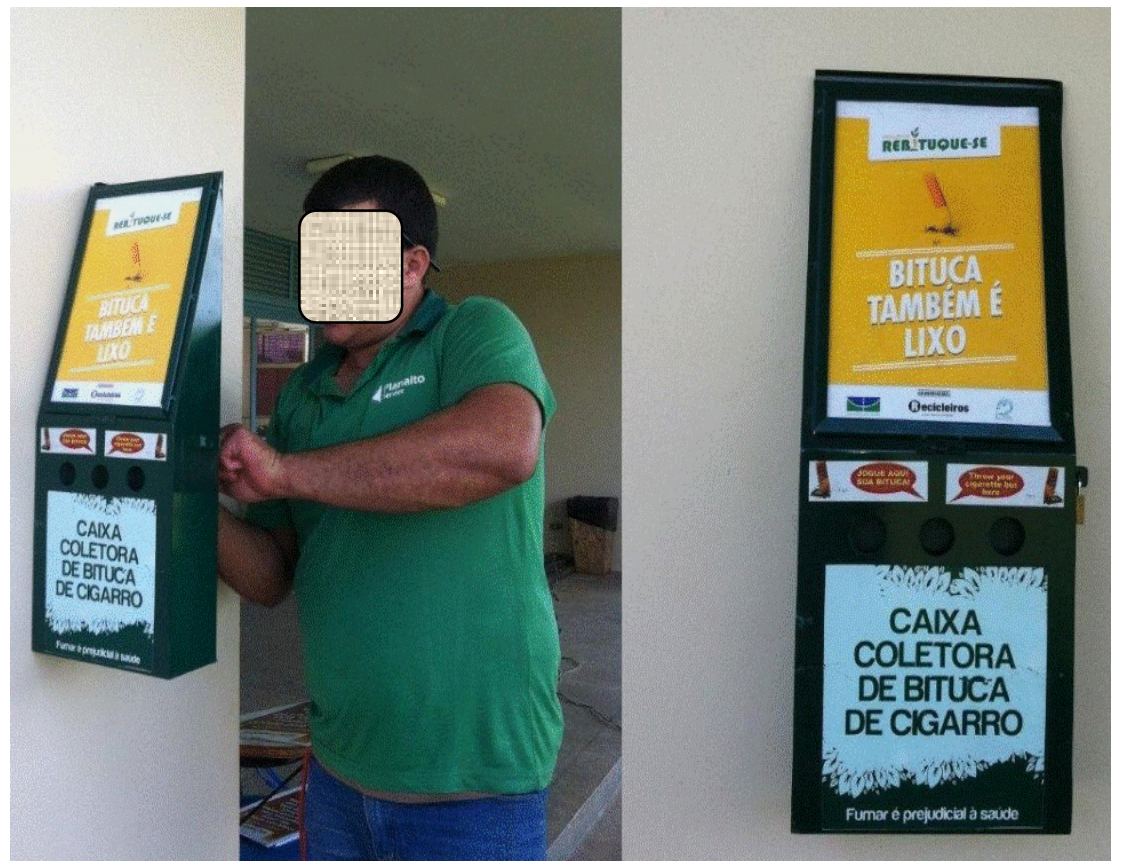

Figura 1. Caixas coletoras de bitucas.

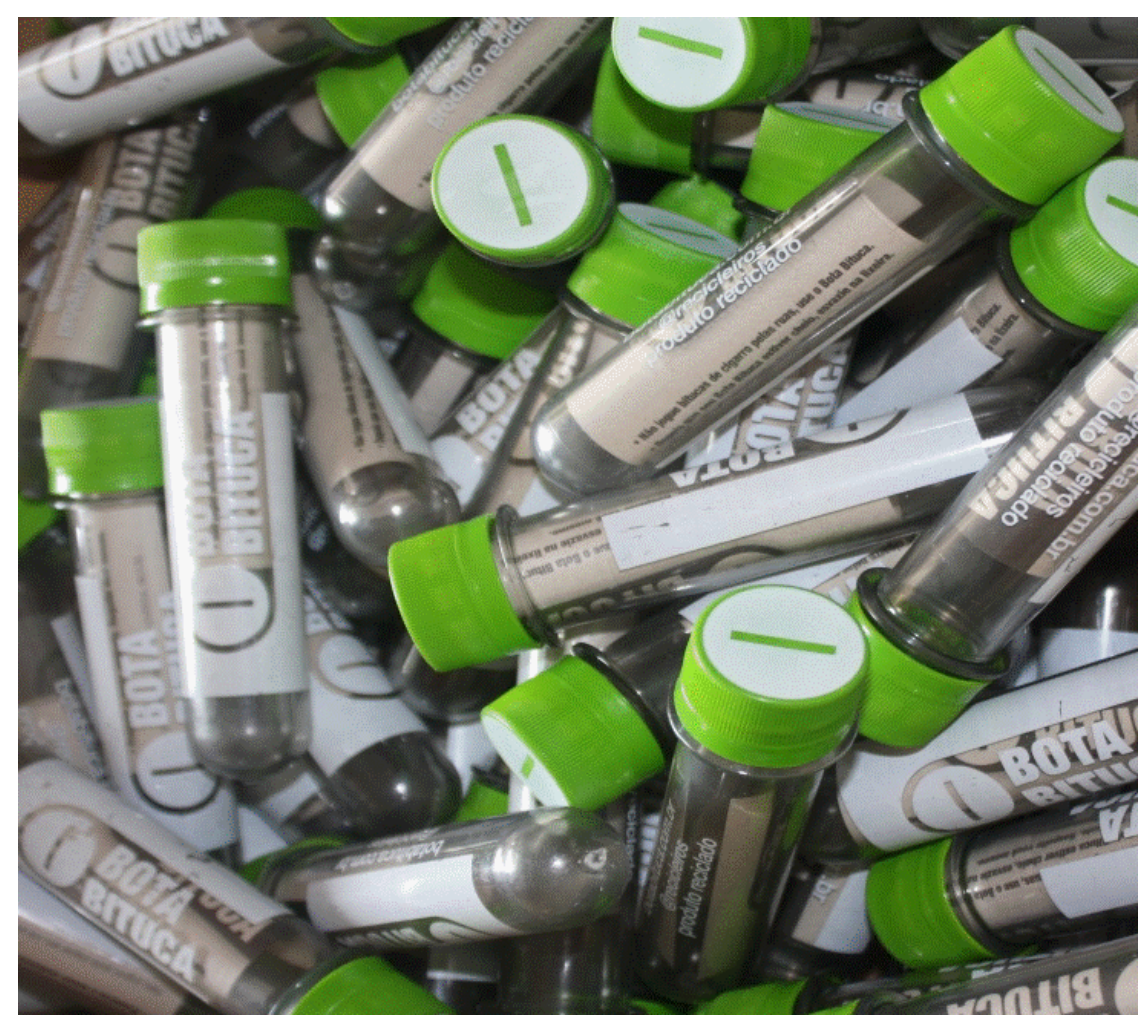

Figura 2. Porta-bitucas portáteis. 


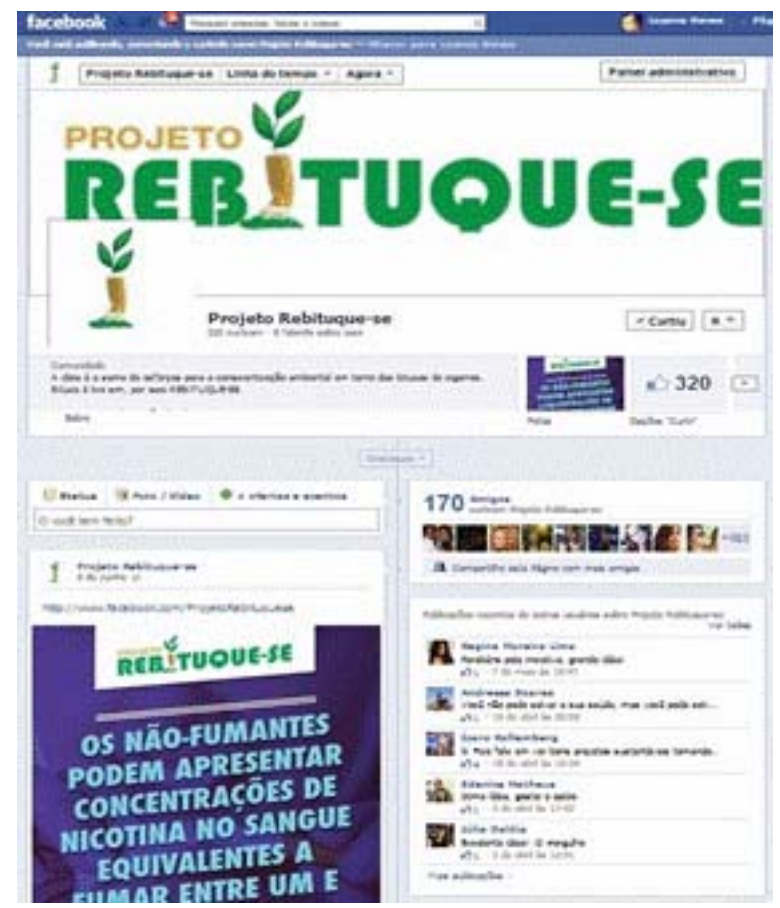

Figura 3. Fanpage do projeto Rebituque-se.

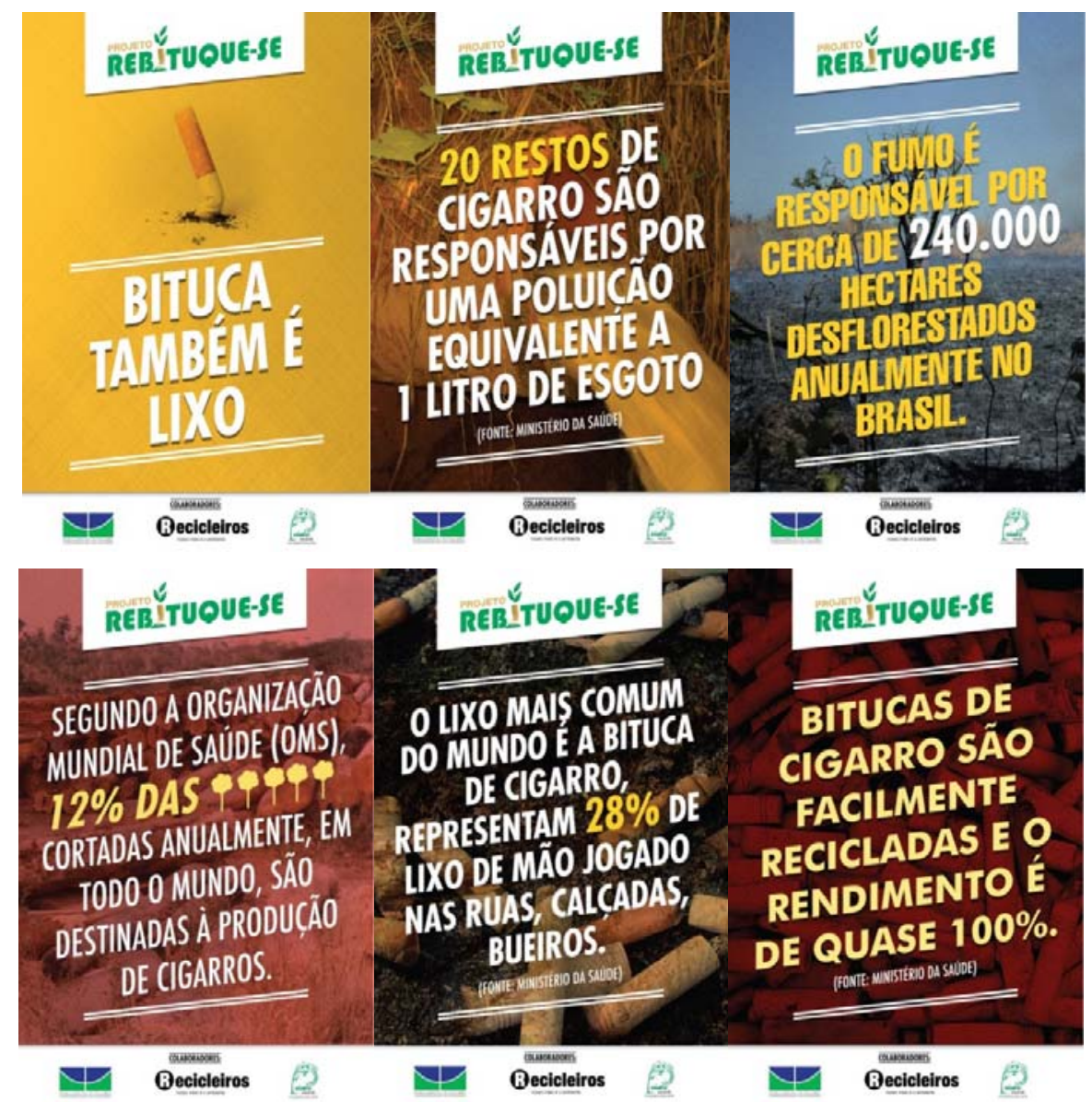

Figura 4. Exemplos de cartazes educativos elaborados. 


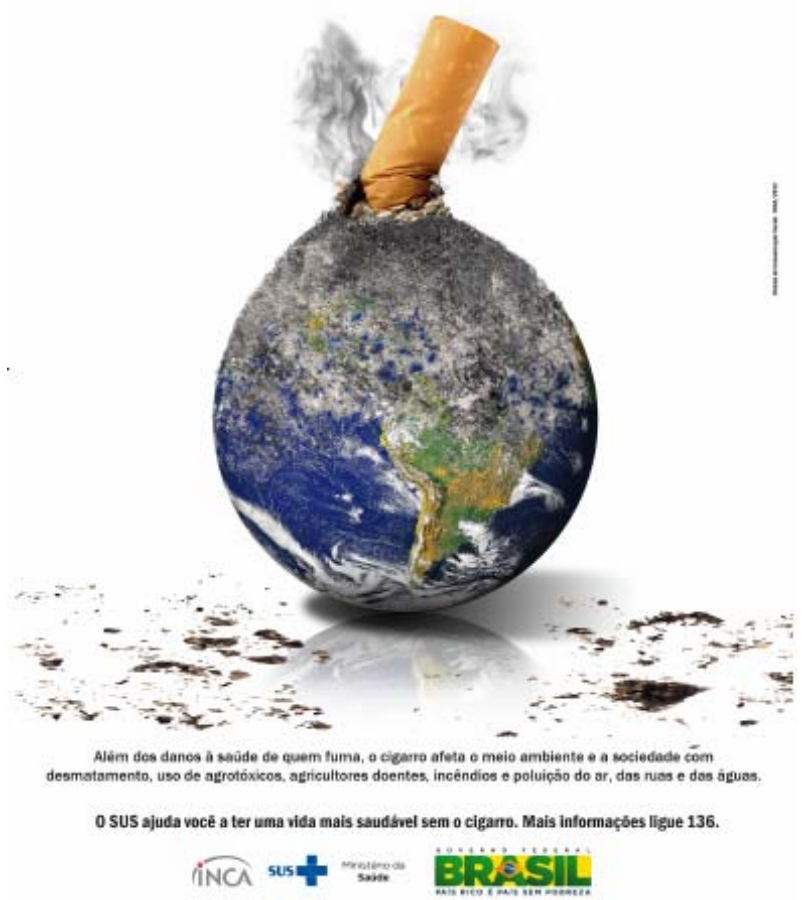

Figura 5. Cartaz fornecido pelo Ministério da Saúde.

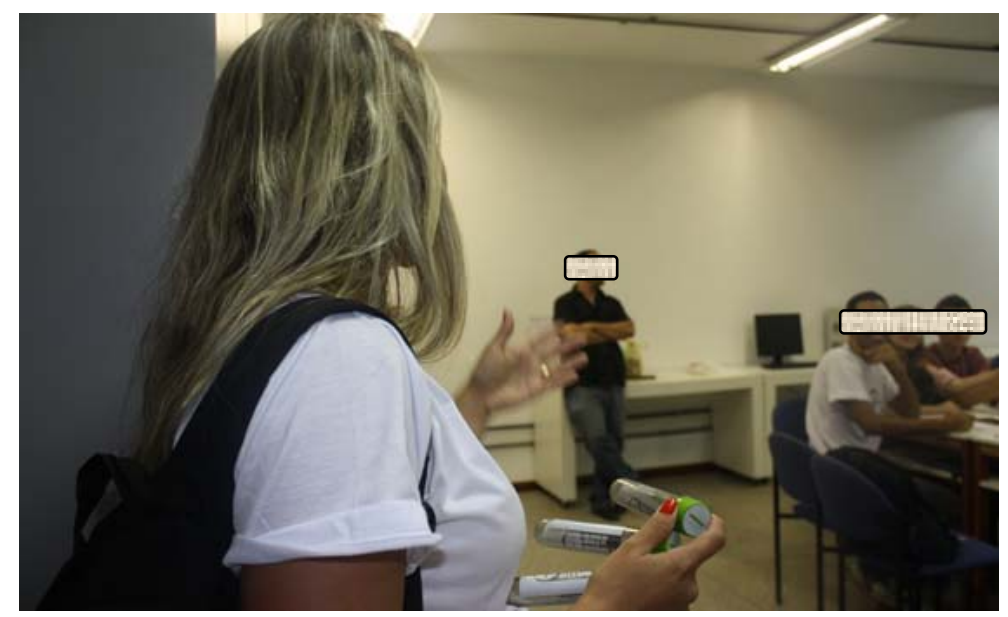

Figura 6. Exposição pessoalmente do assunto.

Tabela 1. Custo dos materiais utilizados no programa de educação ambiental.

\begin{tabular}{ll}
\hline Material & Custo \\
\hline Caixa coletora de bituca (incluído a instalação) & $\mathrm{R} \$ 180,00 \times 4$ unidades \\
Porta-bitucas portáteis & $\mathrm{R} \$ 2,00 \times 200$ unidades \\
Cartazes do Ministério da Saúde & $\mathrm{R} \$ 0,00$ \\
Cartazes educativos criados sobre a bituca de cigarro & $\mathrm{R} \$ 26,00$ \\
\hline Total & $\mathbf{R} \mathbf{1 . 1 4 6 , 0 0}$ \\
\hline
\end{tabular}


foi estruturado em dois blocos de perguntas:

1. Perguntas relacionadas a informações do respondente como, por exemplo: gênero, idade, função na FUP e se fuma ou não. A escala adotada permitiu o respondente assinalar o gênero entre masculino $e$ feminino e sua idade conforme cinco categorias: 1) menos de 20 anos; 2) de 20 a 34 anos; 3) de 35 a 49 anos; 4) de 50 a 64 anos e 5) acima de 64 anos. Em relação às funções na FUP as opções foram: 1) Estudante; 2) Professor; 3) Servidor.
2. Perguntas com o objetivo de avaliar o grau de concordância dos entrevistados em relação às afirmações da Tabela 2 .

Depois de aplicado o questionário, calculou-se a mediana das respostas, obedecendo ao grau de concordância em relação a cada afirmação conforme os valores obtidos pela Escala de Likert (1932): 1 - Discorda Completamente (DC); 2 - Discorda (D); 3 - Indiferente (I); 4 - Concorda $\quad$ (C); 5 - Concorda Completamente (CC).

Tabela 2. Assertivas realizadas para medir a percepção dos entrevistados em relação aos malefícios do cigarro para o meio ambiente e saúde.

\begin{tabular}{l}
\hline 1. As bitucas de cigarro podem ser facilmente recicladas. \\
\hline 2. Bitucas recicladas tornam-se papel artesanal de ótima qualidade. \\
\hline 3. O descarte incorreto das bitucas de cigarro é uma das principais causas dos incêndios florestais. \\
\hline $\begin{array}{l}\text { 4. A etapa de produção do cigarro (plantio, secagem e industrialização do fumo) é extremamente } \\
\text { prejudicial ao meio ambiente. }\end{array}$ \\
\hline 5. As bitucas de cigarro são o lixo mais comum de mão do mundo. \\
\hline 6. O cigarro é extremamente maléfico para saúde. \\
\hline $\begin{array}{l}\text { 7. Os fumantes passivos (não fumantes que inalam fumaça de cigarro) correm o risco de apresentar as } \\
\text { mesmas doenças dos fumantes normais. }\end{array}$ \\
\hline 8. As bitucas presentes no chão afetam a paisagem.
\end{tabular}

As perguntas do questionário foram formuladas de modo que as respostas com alto grau de concordância refletissem um maior conhecimento dos malefícios do cigarro para o meio ambiente e para a saúde, portanto, espera-se que as medianas calculadas antes do programa sejam menores do que as calculadas após a sua execução.

Devido à mensuração dos dados ter sido feita em escala ordinal, para a análise estatística optou-se pelo teste não paramétrico de Mann-Whitney, admitindose um nível de significância de 5\% (Pestana e Gageiro, 2005). Além de análises agregadas, aplicou-se o mesmo teste em análises desagregadas por gênero, idade e hábito de fumar, com o intuito de identificar se o programa aplicado foi mais eficiente conforme os segmentos analisados.

$\mathrm{O}$ teste de Mann-Whitney é rotineiramente calculado por muitos softwares estatísticos como, por exemplo, o SPSS (Pacote Estatístico para Ciências Sociais), utilizado em todas as análises.
Trata-se de um teste relativamente simples, podendo ser verificado suas etapas e fórmulas em Hoffmann (2006).

\section{Avaliação da amostra}

Antes de analisar se a diferença entre as medianas calculadas antes e depois do programa de educação ambiental é estatisticamente significativa e, seguindo as sugestões de Pestana e Gageiro (2005), verificou-se se elas são comparáveis. Para tanto, aplicou-se o teste de aderência do Qui-Quadrado, considerando um nível de significância de 5\%, para comparar se as proporções entre as funções dos membros da FUP (aluno, professor e servidor) são estatisticamente iguais entre as duas amostras coletadas, uma antes e a outra depois do programa de educação ambiental.

Da mesma forma que o teste de Mann-Whitney, o teste de aderência do qui-quadrado é simples e está disponível na maioria dos pacotes estatísticos, podendo ser acompanhado em Hoffmann (2006). 


\section{Resultados e discussões}

\section{Comparabilidade das amostras}

$\mathrm{O}$ perfil da amostra em relação à proporção dos membros da FUP foi similar antes e depois da amostra, em sua maioria composta por estudantes, seguido pelos professores e servidores (Figura 7).

$\mathrm{O}$ teste de aderência do qui-quadrado confirmou, ao nível de significância de $5 \%$, que a proporção dos membros da FUP (aluno, professor ou servidor) é igual nos dois momentos analisados, antes e depois do programa de educação ambiental, indicando que as amostras coletadas são passíveis de comparação conforme esse critério adotado.

\section{Programa de educação ambiental}

As percepções dos entrevistados variaram positivamente após a aplicação do programa de educação ambiental. Verificou-se uma mudança das respostas dos atributos "I" (indiferente) e "D" (discordo) para os atributos "C" (concordo) e "CC" (concordo completamente), aumentando o grau de concordância dos entrevistados em relação à temática abordada e sugerindo um ganho de aprendizado e eficiência do programa aplicado (Figura 8).

O teste não paramétrico de MannWhitney corroborou os resultados da Figura
8, atestando que o programa de educação ambiental aplicado mudou positivamente a percepção dos entrevistados ao nível de significância de 5\%.

Embora constatado uma variação positiva da percepção dos entrevistados, destaca-se o alto grau de conhecimento ambiental do público-alvo antes do programa de educação ambiental, pois a mediana das respostas de $60 \%$ dos entrevistados correspondeu aos atributos "C" e "CC". Para explicar esses resultados iniciais, destaca-se que o campus onde foi realizado o projeto é constituído de cursos (Gestão Ambiental, Ciências da Natureza, Gestão do Agronegócio) onde a temática ambiental é constantemente trabalhada, possivelmente, levando a uma maior ligação dos membros do campus com a natureza.

Conforme Chan e Lau (2000), a ligação emocional das pessoas com o meio ambiente é um dos principais fatores que explicam seu comportamento ambiental nos mais variados aspectos. Portanto, o maior envolvimento dos membros com questões ambientais, certamente, contribuiu com o seu engajamento e interesse no programa aplicado, refletindo no alto aprendizado sugerido pelos resultados.

\section{Antes do Programa de Educação Ambiental}

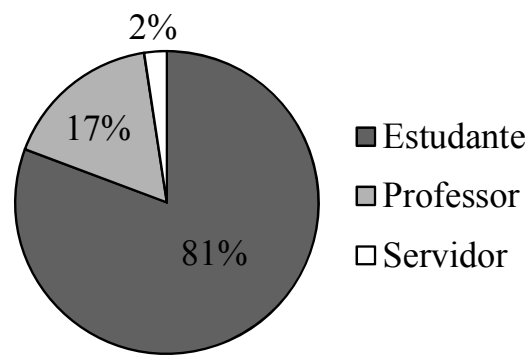

Após o Programa de Educação Ambiental

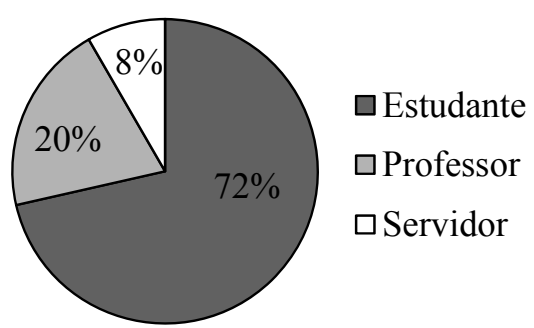

Figura 7. Perfil da amostra em relação à proporção dos membros da FUP antes e depois do programa de educação ambiental. 
Antes do Programa de EA

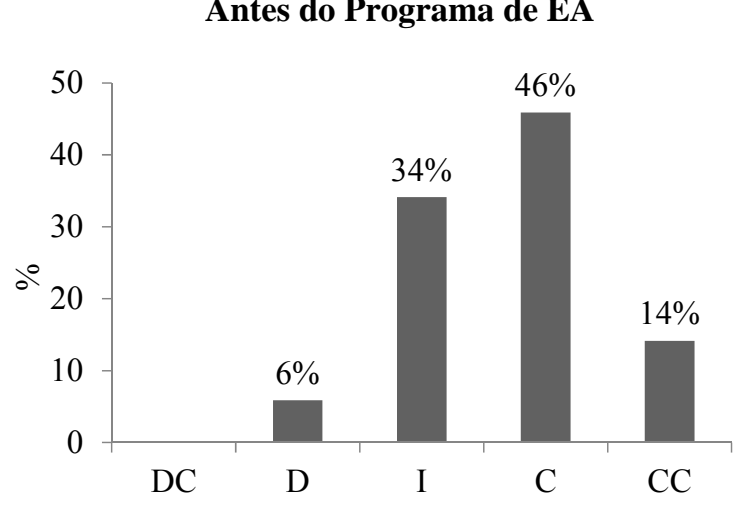

\section{Após o Programa de EA}

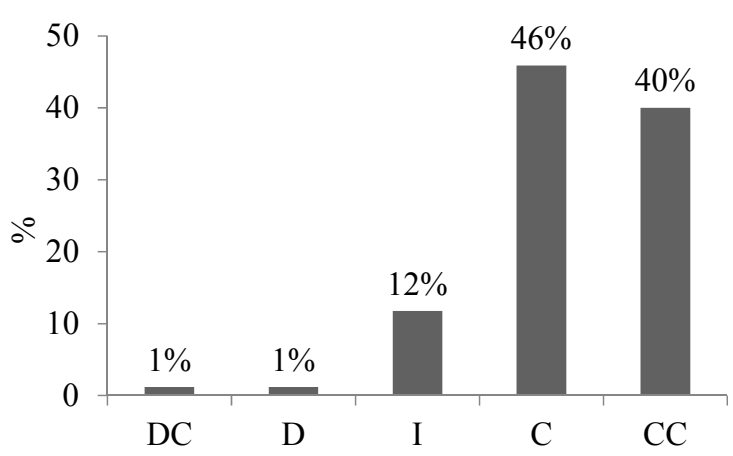

Figura 8. Percepção [com relação a que?] dos entrevistados antes e depois do programa de educação ambiental.

Tabela 3. Resultados do teste de Mann-Whitney para os segmentos analisados.

\begin{tabular}{lcc}
\hline & $\begin{array}{c}\text { Nível exato de } \\
\text { significância }\end{array}$ & $\begin{array}{c}\text { Diferenças significativas ao nível } \\
\text { de } \mathbf{5 \%}\end{array}$ \\
\hline Homens & 0,002 & $\sqrt{ }$ \\
Mulheres & 0,002 & $\sqrt{ }$ \\
Jovens & 0,001 & $\sqrt{ }$ \\
Maduros & 0,006 & $\mathrm{X}$ \\
Não Fumantes & 0,170 & $\sqrt{ }$ \\
Fumantes & 0,001 & \\
\hline
\end{tabular}

\section{Efeito do programa conforme gênero, idade e hábito de fumar}

As análises desagregadas indicaram que, exceto para o público não fumante, o programa de educação ambiental foi eficiente em todos os outros segmentos analisados ao nível de 5\% de significância (Tabela 3). Em outras palavras, os homens, as mulheres, os jovens, os maduros e os fumantes, após o programa de educação ambiental, modificaram significantemente a sua percepção em relação aos danos ocasionados pelas bitucas de cigarro para $o$ meio ambiente e os males do hábito de fumar para a saúde.

Em função da característica da amostra, a análise desagregada para a idade dos entrevistados considerou duas categorias, o público de jovens (até 34 anos) e de maduros (acima de 34 anos). Por ser relativamente recente (inaugurado em maio de 2006), o campus da FUP é composto de uma comunidade jovem. As amostras coletadas não encontraram nenhum membro com idade superior a 64 anos e apenas quatro indivíduos com idade entre 50 e 64 anos, predominando pessoas com idade entre 20 e 34 anos.

Os resultados não significativos ao nível de 5\% para o público não fumante foi esperado, sendo compreensível que esse público tenha tido pouco interesse no programa de educação ambiental implementado, pois o programa é direcionado exclusivamente aos fumantes, não podendo comprovar estatisticamente a eficiência do programa para os que não possuam o hábito de fumar. Naturalmente, o alto conhecimento inicial do público não fumante diante das variáveis analisadas diminui o espaço de aprendizagem e limita a aplicação do teste estatístico (Figura 9). O conhecimento inicial dos não fumantes foi bem superior ao dos fumantes, enquanto $72 \%$ das respostas dos não fumantes, antes 
Não fumantes antes do Programa de EA

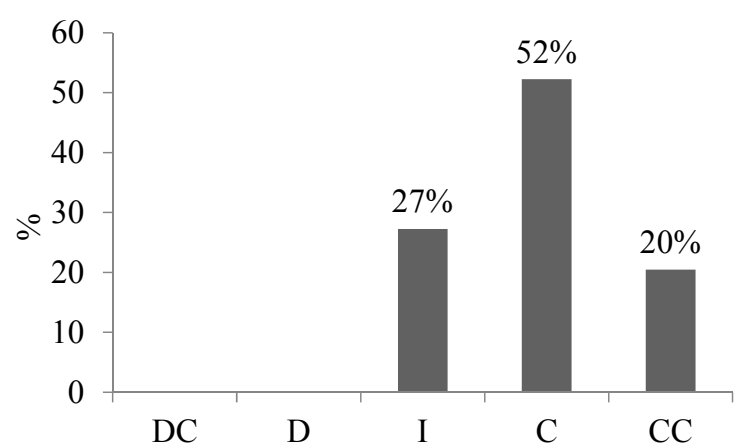

Fumantes antes do Programa de EA

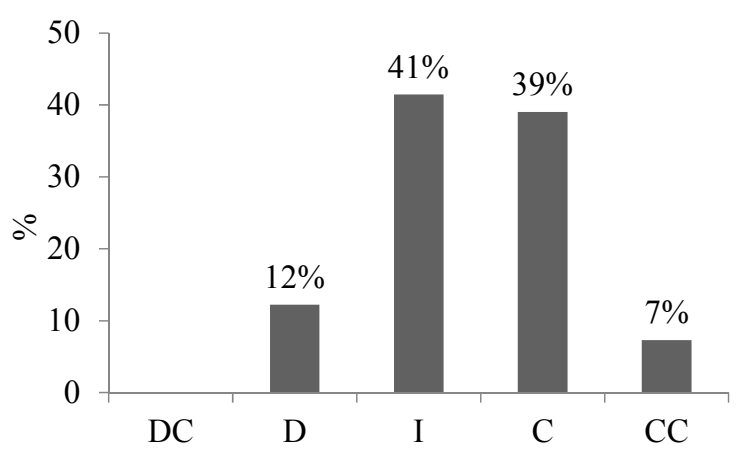

Não fumantes após o Programa de EA

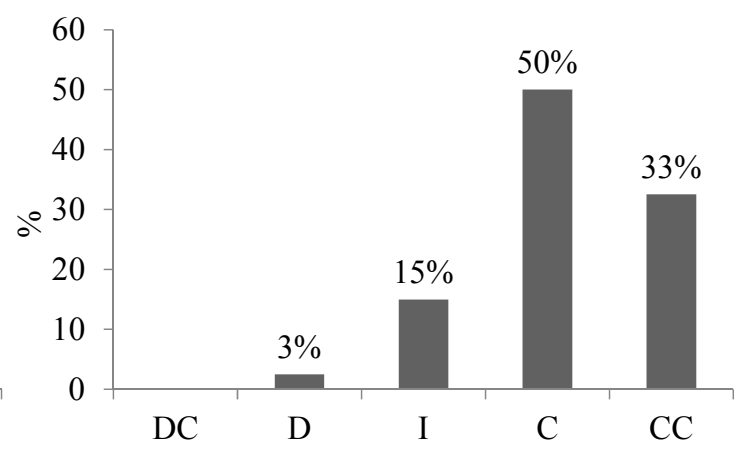

Fumantes após o Programa de EA

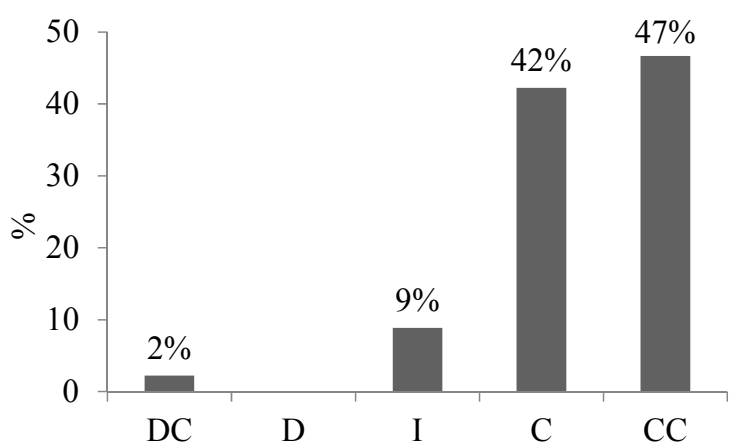

Figura 9. Percepção dos fumantes e não fumantes em relação as assertivas do questionário antes e depois do programa de educação ambiental

da aplicação do programa, estiveram nos atributos "C" e "CC", a porcentagem para os fumantes foi de apenas $46 \%$.

Embora o público não fumante tenha sido exposto ao programa de forma similar ao público fumante, a absorção diferenciada das informações é normal. Para o programa influenciar o público não fumante seria necessária uma mudança no objetivo e na abordagem pedagógica das atividades, saindo de uma orientação voltada para a mudança de comportamento para uma prática capaz de despertar a militância dos envolvidos, pois o comportamento desse público já é adequado aos objetivos do programa, não havendo o que mudar. Sob essa perspectiva, a forma de fazer esse público contribuir seria tornálos membros ativos da causa.

Carvalho (2001) resume bem as práticas da educação ambiental em duas orientações. Segundo a autora, as diferentes práticas da Educação Ambiental (EA) demarcam diferentes orientações que poderiam ser chamadas de EA comportamental e a EA popular. $\mathrm{Na}$ primeira, é valorizado o papel da educação como agente difusor dos conhecimentos sobre o meio ambiente e indutor da mudança dos hábitos e comportamentos considerados predatórios em hábitos $\mathrm{e}$ comportamentos tidos como compatíveis com a preservação dos recursos naturais. A segunda compreende o processo educativo como um ato político no sentido amplo, isto é, como prática social de formação da cidadania. A educação ambiental popular compartilha a idéia de que a vocação da educação é a formação de sujeitos políticos, capazes de agir criticamente na sociedade.

Os resultados percentuais das respostas desagregados pelo gênero foram apresentados na Figura 10. Os resultados para homens e mulheres são próximos, sendo possível verificar uma migração das 
Masculino antes do Programa de EA

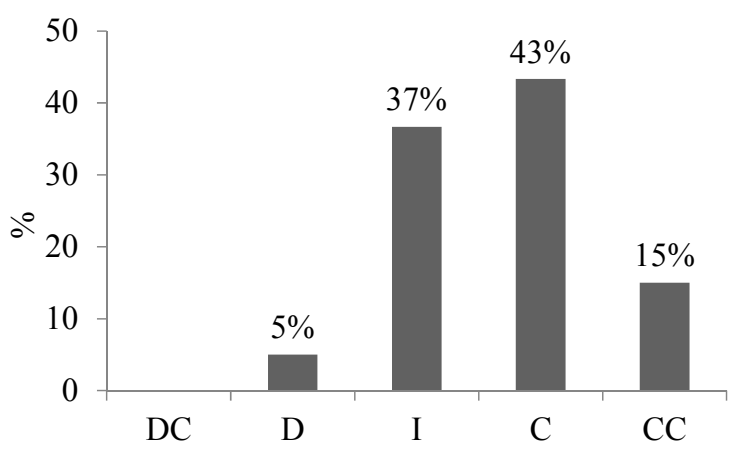

Feminino antes do Programa de EA

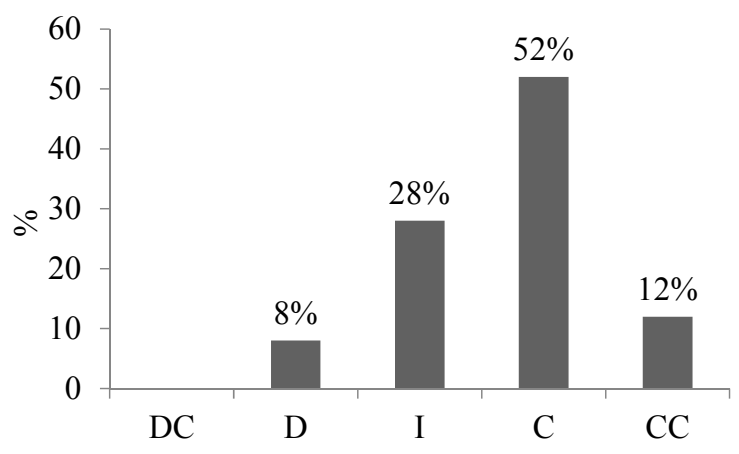

Masculino após o Programa de EA

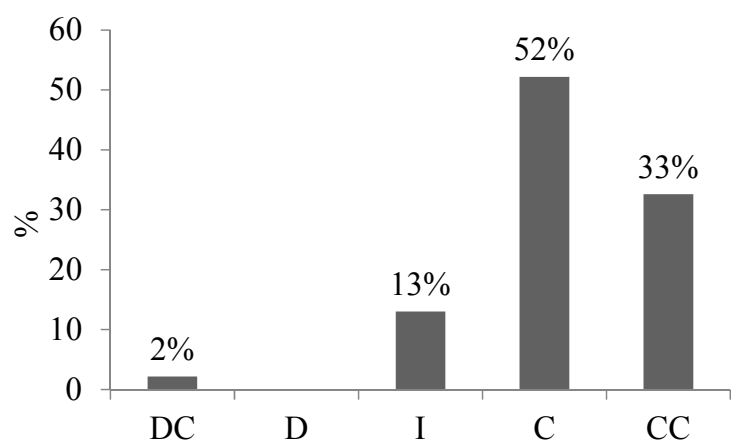

Figura 10. Percepção dos homens e mulheres em relação as assertivas do questionário antes e depois do programa de educação ambiental.

respostas dos atributos indicativos de baixo conhecimento "I" e "D" para os de alto conhecimento "C" e "CC" em uma magnitude semelhante, em torno de 25 pontos percentuais $(27 \%$ para homens e $23 \%$ para mulheres). Os resultados indicaram que as práticas pedagógicas adotadas foram adequadas para ambos os públicos, sugerindo ser desnecessária qualquer modificação no programa aplicado com vista a atender particularidades relacionadas ao gênero dos indivíduos.

$\mathrm{O}$ comportamento masculino e feminino perante as questões ambientais é controverso na literatura. Alguns estudos sugerem que as mulheres tendem a ser ecologicamente mais conscientes que os homens, como, por exemplo, Banerjee e McKeage (1994) e Mainieri et al. (1997). Opostamente, Balderjahn (1988) e LingYee (1997) encontraram resultados favoráveis para o público masculino. Já
Afonso (2010), não encontrou resultados estatisticamente significativos que diferenciassem o comportamento ambiental conforme o gênero do indivíduo. Os resultados encontrados em conjunto com as referências analisadas sugerem que é desnecessário tratar de forma diferenciada o público feminino do masculino em relação à estrutura dos programas de educação ambiental, guardadas as devidas limitações inerentes às características da amostra. Entretanto, em uma abordagem que privilegie uma análise mais qualitativa desta perspectiva, a tendência apontada pela literatura, de que mulheres adotam comportamentos mais ecologicamente equilibrados, pode ser investigada mais detidamente.

Os resultados desagregados por idade foram semelhantes aos encontrados por gênero, não sendo possível encontrar grandes diferenças entre $o$ efeito do 
programa de educação ambiental no público jovem e maduro. Além do teste de MannWhitney confirmar ao nível de $5 \%$ de significância a mudança positiva de percepção em ambas as faixas etárias analisadas, a Figura 11 sugere um grau de conhecimento inicial e após o programa em magnitude semelhante para os jovens e maduros. Antes do programa de educação ambiental, em torno de $40 \%$ do público jovem e maduro responderam as perguntas do questionário nos atributos "I" e "D", reduzindo esse percentual para cerca de $10 \%$ após o programa.

\section{Jovens antes do Programa de EA}

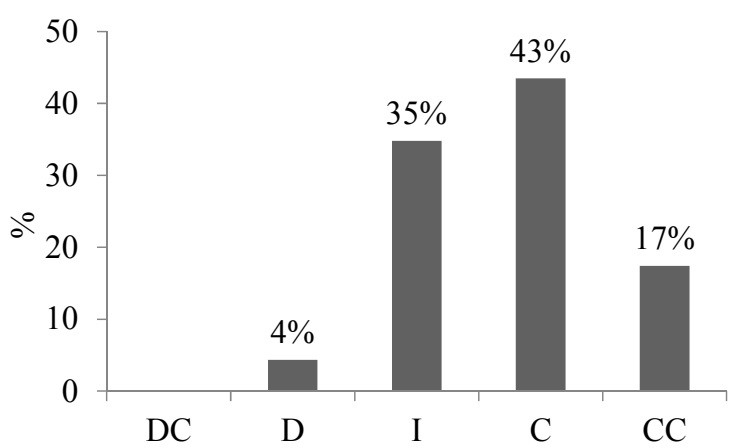

Maduros antes do Programa de EA

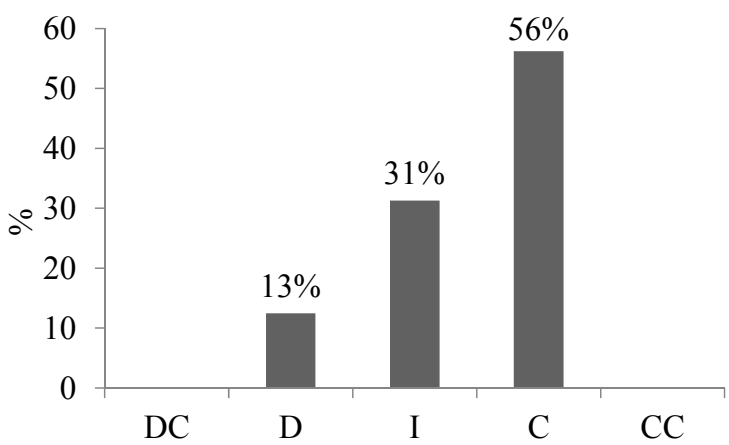

Jovens após o Programa de EA

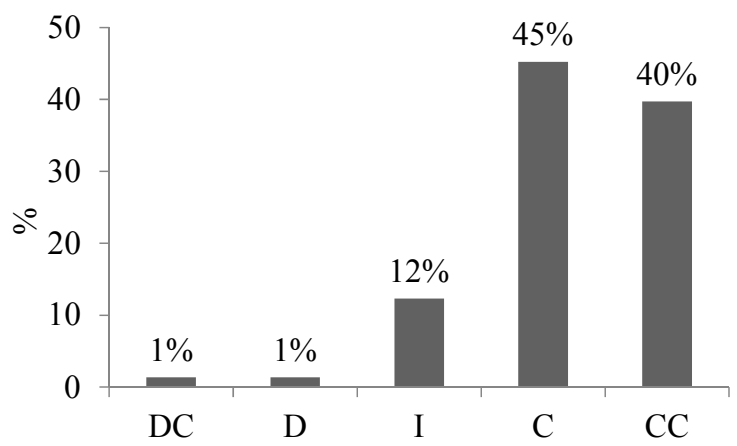

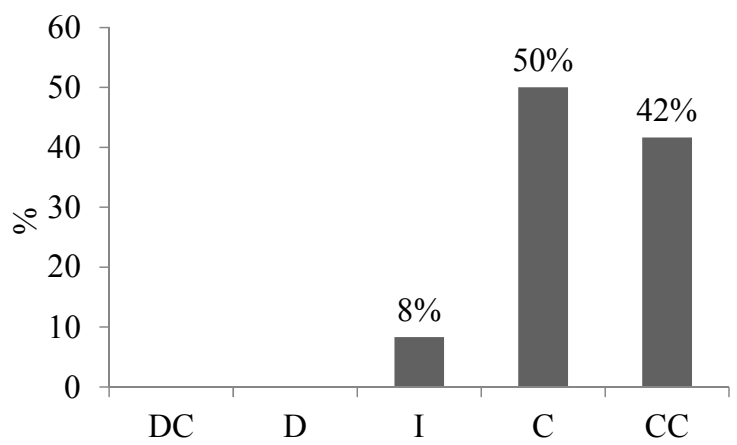

Figura 11. Percepção dos jovens e maduros em relação as assertivas do questionário antes e depois do programa de educação ambiental.

Tal como os resultados para o gênero, as evidências empíricas disponíveis na literatura em relação ao comportamento ambiental conforme a idade é contraditória. Por exemplo, Straughan e Roberts (1999) encontraram relação significativa entre idade e comportamento ambiental, já os resultados de Afonso (2010) não identificaram essa relação. Segundo esse autor, as variáveis sociodemográficas inerentes ao gênero e idade não são relevantes para explicar o comportamento do consumidor ecologicamente consciente, sendo esse comportamento influenciado principalmente por variáveis psicográficas como, por exemplo, "a eficácia percebida de suas ações". Em outras palavras, pouco importa se o indivíduo é homem ou mulher, se é jovem ou velho, o que determina a adoção dele por um comportamento ambientalmente favorável é a crença de que as suas ações têm um papel importante no combate à degradação ambiental.

Os resultados encontrados em conjunto com a revisão da literatura sugerem que particularidades inerentes ao 
gênero e à idade são pouco importantes na elaboração das práticas pedagógicas do programa de educação ambiental aplicado e, talvez, trabalhar questões psicográficas, como a eficácia percebida das ações, seja um eixo importante a ser considerado em programas dessa natureza.

A importância de variáveis psicográficas na elaboração de um programa de educação ambiental é bem apresentada no trabalho de Lopes et al. (2011). Os autores concluíram que o fracasso de várias atividades de cunho ambiental realizadas em uma escola rural ocorreu devido à desconsideração do preconceito normalmente sentido pelos estudantes. Pois, o meio rural ainda é visto como área atrasada e não desenvolvida pelas pessoas da cidade e, isso, de alguma forma, desestimulava e inibia o aluno da escola rural em participar das iniciativas de educação ambiental, limitando a eficiência dos programas implementados.

Mas, ainda assim, deve-se considerar que o recorte de gênero e idade tem ficado cada vez mais forte no tema da educação ambiental, podendo ser importante a sua consideração dependendo da complexidade dos objetivos proposto, bem como, do contexto que envolve o público alvo do programa.

Um exemplo a ser destacado, que buscou considerar as diferenças entre gênero e idade no desenvolvimento de ações de educação ambiental, foi a IV Conferência Nacional Infanto-Juvenil pelo Meio Ambiente, promovida pelo Ministério da Educação/ Secretaria de Educação Continuada, Alfabetização, Diversidade e Inclusão. Essa conferência é voltada para as escolas com pelo menos uma turma do $6^{\circ}$ ao $9^{\circ}$ ano do Ensino Fundamental, públicas e privadas, urbanas e rurais, da rede estadual ou municipal, assim como escolas de comunidades indígenas, quilombolas e de assentamento rural (MEC, 2013) e seu objetivo é:

Propiciar atitude responsável e comprometida da comunidade escolar com as questões socioambientais locais e globais, com ênfase na participação social e nos processos de melhoria da relação ensino-aprendizagem, em uma visão de educação para a sustentabilidade e o respeito à diversidade. (MEC, 2013: 19).

A questão que esse fato coloca em relação ao debate da literatura e aos resultados apresentados neste artigo é que é preciso investigar mais a fundo as percepções que envolvem as dimensões relativas à idade e ao gênero. No contexto de aplicação do programa implementado as diferenças relativas a essas dimensões não foram notadas, entretanto, a pesquisa quanto os danos das bitucas de cigarro para o meio ambiente e os males do hábito de fumar para saúde pode ser aprofundada considerando-se uma triangulação de métodos, para esse caso, cabe o uso de outras técnicas de coleta de dados (entrevistas, análises de contextos, etc.) fazendo um cotejamento das possibilidades de compreensão da eficiência do programa de maneira a considerar um olhar mais aprofundado da realidade em questão e possibilitando uma aplicação mais adequada a cada um dos contextos em que o programa pode ser aplicado. Ravallion (2001) utiliza-se da possibilidade de triangulação de método para esse tipo de interpretação.

\section{Conclusões}

- A estruturação do programa de educação ambiental foi bem simples e, embora o assunto tratado seja complexo e multidisciplinar, não demandou vultosos recursos ou mão de obra extremamente especializada.

- Por ser um tema bem aceito, a aplicação do programa foi facilitada pela boa vontade das pessoas na "abertura de portas", na participação e no patrocínio de equipamentos, revelando uma dificuldade inferior à esperada. Naturalmente, deve ser acrescentado que a realização de qualquer pesquisa dentro de um campus universitário, principalmente, uma pesquisa relacionada ao tema "educação" é facilitada. 
- Apesar de modesto e rápido, o programa de educação ambiental alcançou resultados contundentes na mudança de percepção das pessoas diante dos danos das bitucas de cigarro para o meio ambiente e dos males do hábito de fumar para a saúde.

- Independente do gênero ou idade, o programa foi eficiente e mostrou a necessidade de melhorar o entendimento do comportamento desses segmentos diante da implementação de um programa de educação ambiental. Assim, sugere-se que estudos com o uso de outros métodos sejam desenvolvidos para a compreensão das variáveis gênero e idade na construção de programas de educação ambiental.

- Não foi possível comprovar resultados contundentes do programa em indivíduos não fumantes, indicando a necessidade da adoção de outras práticas pedagógicas, caso o objetivo seja tornar esse grupo de pessoas como militantes de uma causa ambiental orientada para os males do cigarro para o meio ambiente e saúde.

\section{Agradecimentos}

Aos alunos da FUP, Erica Pacher Ferreira e Daniel Bruno Matheoli. Eles que fizeram o programa de educação ambiental supracitado acontecer.

\section{Declaração de conflito de interesses}

Os autores declaram não haver conflitos de interesses.

\section{Referências}

Afonso, A. C. B. O consumidor verde: perfil do comportamento de compra. Lisboa: Universidade Técnica de Lisboa, Instituto Superior de Economia e Gestão, 2010. (Dissertação de Mestrado em Marketing). Disponível em: <http://www.repository.utl.pt/ bitstream/10400.5/1758/1/Tese_Ana Carolina Baptista Afonso.pdf $>$. Acesso em: 05 maio 2016.

Balderjahn, I. Personality variables and environmental attitudes as predictors of ecologically responsible consumption patterns. Journal of Business Research, v. 17, n. 1, p. 51-56, 1988. http://dx.doi.org/10.1016/01482963(88) 90022-7

Banerjee, B.; McKeage, K. How green is my value: exploring the relationship between environmentalism and materialism. Advances in Consumer Research, v. 22, p. 257-261, $1994 . \quad$ Disponível em: $<$ http://www.acrwebsite.org/volumes/7575/volu mes/v21/NA-21>. Acesso em: 05 maio 2016.

Carvalho, I. C. M. Qual Educação Ambiental? Elementos para um debate sobre educação ambiental e extensão rural. Agroecologia e Desenvolvimento Rural Sustentável, v. 2, n. 2, p. 43-51, 2001. Disponível em: $<$ http://www.emater.tche.br/site/multimidia/ leitor/7.php\#book/43>. Acesso em: 05 maio 2016.

Chan, R.; Lau, L. Antecedents of green purchases: a survey in China. Journal of Consumer Marketing, v. 17, n. 4, p. 338-357, 2000. http://dx.doi.org/10.1108/07363760010335358

Czapski, S. A implantação da Educação Ambiental no Brasil. Brasília: Coordenação de Educação Ambiental, Ministério da Educação e do Desporto, 1998. Disponível em: $<$ http://www.icmbio.gov.br/educacaoambiental/ images/stories/biblioteca/educacao_ambiental/ A_implantação_da_EA_no_Brasil.pdf $>$. Acesso em: 05 maio 2016 .

Hoffmann, R. Estatística para economistas. 4. ed. São Paulo: Pioneira Thomson Learning, 2006.

Layrargues, P. P. A natureza da ideologia e a ideologia da natureza: elementos para uma sociologia da Educação Ambiental. Campinas: Universidade de Campinas, 2003. (Tese de doutorado em Ciências Sociais).

Likert, R. A technique for the measurement of attitudes. Archives of Psychology, v. 22, n. 140, p. 1-55, 1932. Disponível em: $<$ http://www.voteview.com/pdf/Likert_1932.pdf $>$. Acesso em: 05 maio 2016.

Ling-Yee, L. Effect of collectivist orientation and ecological attitude on actual environmental commitment: the moderating role of consumer demographic and product involvement. Journal of International Consumer Marketing, v. 9, n. 4, p. 31-53, 1997. http://dx.doi.org/10.1300/J046v09n04_03

Lopes, P. R.; Souza, I. F.; Leme. M.; Brandão, J. A. V.; Costa, R. M. G. F.; Figueiredo, R. A. Diagnóstico socioambiental: o meio ambiente percebido por estudantes de uma escola rural de 
Araras (SP). Pesquisa em Educação Ambiental, v. 6, n. 1, p. 139-155, 2011.

Mainieri, T.; Barnett, E. G.; Valdero, T. R.; Unipan, J. B.; Oskamp, S. Green buying: the influence of environmental concern on consumer behavior. The Journal of Social Psychology, v. 137, n. 2, p. 189-204, 1997.

MEC - Ministério da Educação. IV Conferência Nacional Infanto-Juvenil pelo Meio Ambiente (Regulamento). Disponível em: $<$ http://conferenciainfanto.mec.gov.br/images/ pdf/regulamento_conferencia.pdf $>$. Acesso em: 7 nov. 2013.

Pedrini, A. G.; Brotto, D. S.; Messas, T. P. Avaliação de aproveitamento no I Curso de Atualização em EA para o Turismo Marinho e Costeiro (I CEAM). Revista Eletrônica do Mestrado em Educação Ambiental, v. 28, p. 133-147, 2012. Disponível em: $<$ http://www.seer.furg.br/remea/article/download/ 3110/1781>. Acesso em: 05 maio 2016.

Pestana, M. H; Gageiro, J. N. Análise de dados para Ciências Sociais: a complementaridade do SPSS. 4. ed. Lisboa: Edições Silabo, 2005.

Ravallion, M. The mystery of the vanishing benefits: an introduction to impact evaluation. The World Bank Economic Review, v. 15, n. 1, p. 115-140, 2001.

Santos, N. L.; Silva, M. M. P. Por que Educação Ambiental não tem alcançado mudanças significativas na sociedade contemporânea? Uma análise de artigos publicados em eventos científicos no Brasil de 2005 a 2010. Revista Eletrônica do Mestrado em Educação Ambiental, v. 7, p. 122-138, 2011. Disponível em: $\quad<$ http://www.seer.furg.br/remea/article/ download/3198/1860>. Acesso em: 05 maio 2016.
Silva, A. S. Educação Ambiental: aspectos teóricos-conceituais, legais e metodológicos. Educação em Destaque, v. 1, n. 2, p. 45-61, 2008.

Silva, M. M. P.; Leite, V. D. Estratégias para realização de Educação Ambiental em escolas do ensino fundamental. Revista Eletrônica do Mestrado em Educação Ambiental, v. 20, p. 372-392, 2008. Disponível em: $<$ http://www.seer.furg.br/remea/article/download/ 3855/2299>. Acesso em: 05 maio 2016.

Straughan, R. D.; Roberts, J. A. Environmental segmentation alternatives: a look at green consumer behaviour in the new millennium. Journal of Consumer Marketing, v. 16, n. 6, p. 558-575, 1999.

Trajber, R.; Costa, L. B. Avaliando a Educação Ambiental no Brasil: materiais audiovisuais. São Paulo: Peirópolis/Instituto Ecoar para a Cidadania, 2001

Informação da Licença: Este é um artigo Open Access distribuído sob os termos da Licença Creative Commons Attribution, que permite uso irrestrito, distribuição e reprodução em qualquer meio, desde que a obra original seja devidamente citada. 